Article

\title{
Electrochemical Characterization of a Polymer Inclusion Membrane Made of Cellulose Triacetate and Aliquat 336 and Its Application to Sulfonamides Separation
}

\author{
Juana Benavente ${ }^{1, *}$, Virginia Romero ${ }^{1}$, María Isabel Vázquez ${ }^{1}$, Enriqueta Anticó ${ }^{2}$ and \\ Clàudia Fontàs ${ }^{2}$ \\ 1 Departamento de Física Aplicada I, Facultad de Ciencias, Universidad de Málaga, E-29071 Málaga, Spain; \\ virgirom@uma.es (V.R.); mvazquez@uma.es (M.I.V.) \\ 2 Department of Chemistry, University of Girona, C/M. Aurèlia Capmany 69, 17003 Girona, Spain; \\ enriqueta.antico@udg.edu (E.A.); claudia.fontas@udg.edu (C.F.) \\ * Correspondence: j_benavente@uma.es; Tel.: +34-952-131929
}

Received: 23 November 2017; Accepted: 20 December 2017; Published: 15 January 2018

\begin{abstract}
An electrochemical characterization of a polymer inclusion membrane (PIM) fabricated with the ionic liquid (IL) Aliquat $336(26 \%)$ and the polymer cellulose triacetate (CTA) $(76 \%)$ is presented. Considering the use of PIMs in separation systems to remove pollutants from water, the characterization was performed with $\mathrm{NaCl}$ solutions by measuring membrane potential, electrochemical impedance spectroscopy, and salt diffusion and results were compared with those obtained from dry membranes. Results showed a significant reduction in the membrane diffusive permeability and electrical conductivity as well as the transport number of cation $\mathrm{Na}^{+}$across the PIM when compared with solution values, which could be mainly related to the dense character of the membrane. Membrane application in the separation of different sulfonamides (sulfathiazole, sulfapyridine, sulfamethazine, and sulfamethoxazole) from water, with $1 \mathrm{M} \mathrm{NaCl}$ solution as striping phase, was also considered. These results indicated that the different chemical characteristics of the compounds, as well as the compact structure of the PIM, limited the transport of the organic molecules though it.
\end{abstract}

Keywords: polymer inclusion membrane; Aliquat 336; membrane potential; impedance spectroscopy; sulfonamides

\section{Introduction}

As it is well known, ionic liquids (ILs) are salts composed of an organic cation and an inorganic/organic anion with very low vapor pressure, low solubility, good electrical conductivity, and thermal stability [1], which allow their use in a large number of different applications such as solvents for organic reactions and catalysis, energy, electro-deposition, green chemistry, separation processes or $\mathrm{CO}_{2}$ capture, among others [2-9]. Moreover, ILs can be used as extractants in the preparation of polymer inclusion membranes (PIMs). PIMs basically consist of a polymeric matrix, normally made of cellulose triacetate (CTA) or poly(vinyl chloride) (PVC) $[10,11]$ and an extractant (named carrier), which is responsible for transport across the membrane. Usually the addition of a plasticizer or some modifiers is needed to obtain adequate elastic characteristics of the membranes [12]. However, the use of ILs as carriers favors the flexibility and mechanical strength of PIMs avoiding the need of the addition of other components, and their high viscosity helps to retain them in the polymer gel-like network. Different commercial ILs such as Cyphos 101 (trihexyl(tetradecyl)phosphonium chloride), Cyphos 102 (trihexyl(tetradecyl)phosphonium bromide), 
Cyphos 104 (trihexyl(tetradecyl)phosphonium bis-2,4,4-(trimethylpentyl) phosphinate), or Aliquat 336 (trioctylmethyl ammonium chloride) have been reported as carriers in PIMs used in the separation of metal species such as $\mathrm{Cd}, \mathrm{Cu}$, or In, organic compounds such as antibiotics or water pollutants [13-17].

In previous works, different physicochemical characteristics of PIMs (contact angle, Young modulus, conductivity, or dielectric constant) were analyzed for membranes containing different Aliquat 336 (AlqCl) percentages in both CTA or PVC polymers [18], as well as for PIMs where the counter-anion of Alq was modified ( $\mathrm{AlqCl}, \mathrm{AlqNO}_{3}$ or AlqSCN) [19]. However, information on other electrochemical characteristic parameters, such as ion transport numbers or ionic diffusion coefficients $[20,21]$, determined from measurements carried out with PIMs in contact with saline solutions seems to be also of interest for their applications.

Thus, in this study an electrochemical characterization of an Aliquat 336/CTA PIM (26\% $\mathrm{AlqCl} / 74 \% \mathrm{CTA}$ ) is presented performed by membrane potential and impedance spectroscopy measurements using a typical model electrolyte $(\mathrm{NaCl})$ at different solution concentrations. A comparison of other physicochemical parameters depending on the PIM state (dry or wet) is also indicated to have a more adequate picture of the membrane behavior in usual working conditions for water treatment.

Separation abilities of the characterized PIM are studied using a mixture of four common antibiotics, belonging to the sulfonamides family, which can be found in natural waters due to their wide use and incomplete elimination through sewage treatment.

\section{Results and Discussion}

Taking into account that PIMs are aimed to transport and separate compounds of interest in aqueous solution, it is important to determine their physicochemical characteristics in a wet media and to compare them with respect to dry membranes. It is important to bear in mind that PIMs can lose part of the IL incorporated in the polymeric network when membranes are immersed in distilled water or aqueous electrolyte solutions [22,23]. This mass loss is associated with both the nature of the IL and the polymer. In particular, Kagaya et al. [23] found a relative mass loss of around 20\% for an Aliquat $336 /$ PVC membrane after $48 \mathrm{~h}$ immersion in distilled water. However, the mass loss diminished to $2 \%$ when immersed in a $\mathrm{NaCl}$ solution.

In this study, chemical surface differences between a wet PIM (sample $26 \% \mathrm{AlqCl} / 74 \% \mathrm{CTA}-\mathrm{w}$, $\mathrm{w}$ indicating 'wet state', that is, after $48 \mathrm{~h}$ immersed in distilled water) and a dry PIM (sample $26 \%$ Alq336/74\% CTA-d, d indicating 'dry state') was determined by analyzing X-ray photoelectron spectroscopy (XPS) spectra. XPS is a well-known technique able to give information on chemical changes on membrane surfaces since it provides elemental identification, relative composition, and chemical state of the elements present in a surface region [24]. Consequently, differences in the atomic concentration percentages (A.C. \%) determined for the elements found on the surfaces of wet and dry membrane samples should be an indication of Aliquat 336 modification/lost. Table 1 shows the A.C. \% of the elements present on the surfaces of the PIMs $(\mathrm{C}, \mathrm{O}, \mathrm{N}, \mathrm{Cl}$, and $\mathrm{Si})$ in dry and wet states (samples 26\% AlqCl/74\% CTA-d and 26\% AlqCl/74\% CTA-w), which were determined by analyzing the XPS spectra. Moreover, A.C. $\%$ of the elements found on the surface of a CTA film in dry and wet states (CTA-d and CTA-w samples, respectively) are also indicated in Table 1 for comparison reasons. As expected, both CTA-films do not show any $\mathrm{Cl}$ content since this element is associated to Aliquat 336. However, $\mathrm{Si}$, a non-characteristic membrane/film element, is detected in all samples. This fact can be attributed to a manufacture contamination, and its higher percentage in wet samples might be related to element surface reorganization associated to the hydrophobic character of silica $[25,26]$. In fact, surface reorganization of more hydrophobic organic matter and $\mathrm{N}$ impurities could be one of the reasons for differences between dry and wet samples. In this context, it should also be indicated that the total N (\%) obtained for dry and wet PIM samples also seems to include contamination contribution, while the specific Aliquat 336-N contribution (binding energy at $402.2 \mathrm{eV}$ [27]) is indicated in brackets. In that case, the $\mathrm{N} / \mathrm{Cl}$ ratio is similar to the theoretical one 
$\left((\mathrm{N} / \mathrm{Cl})^{\mathrm{T}}=1\right)$. Consequently, the comparison of the results obtained for wet and dry PIM samples shows a reduction in the percentages of $\mathrm{Cl}$ and $\mathrm{N}$ associated to Aliquat 336 in the wet sample (around $25 \%$ ). This fact seems to indicate a partial loss of the IL from the membrane surface, but the effect of element surface reorganization depending on their higher/lower hydrophobic character might also be involved.

Table 1. Atomic concentration percentages of the elements found * on the surfaces of wet (X-w) and dry (X-d) PIM or CTA film.

\begin{tabular}{cccccc}
\hline PIM & C (\%) & O (\%) & N (\%) & Cl (\%) & Si (\%) \\
\hline $26 \%$ AlqCl/74\% CTA-w & 72.6 & 23.7 & $1.6(0.38)$ & 0.31 & 1.6 \\
$26 \%$ AlqCl/74\% CTA-d ${ }^{a}$ & 66.7 & 29.6 & $0.89(0.50)$ & 0.44 & 0.3 \\
CTA-w & 73.7 & 24.1 & 0.65 & n.d. & 1.6 \\
CTA-d & 66.6 & 32.3 & n.d. & n.d. & 0.9 \\
\hline
\end{tabular}

* Other elements with A.C. $\%<0.3$ are not indicated; ${ }^{\text {a }}$ values from reference [18]. n.d. = not detected.

Wet PIMs also exhibit different elastic behavior than dry ones, as can clearly be observed in Figure 1, where a comparison of the strain-stress/elongation curves for wet and dry PIM samples is presented. Wet PIM sample shows a more plastic character, with a significant increase in the elongation at break (around eight times higher) and lower Young modulus (40\% reduction), which is determined from the slope of the linear relationship obtained at low strain-stress values (insert in Figure 1). These changes are attributed to the plasticizer character of water, as it was previously obtained for regenerated cellulose membranes [28]. This fact should be considered in the selection of the Aliquat 336 content used for PIM manufacture, since it can play an important role on the mechanical behavior (high plasticity or brittle) of the membranes, according to the significant reduction in Young modulus associated to Aliquat 336 content in dry AlqCl/CTA membranes [18].

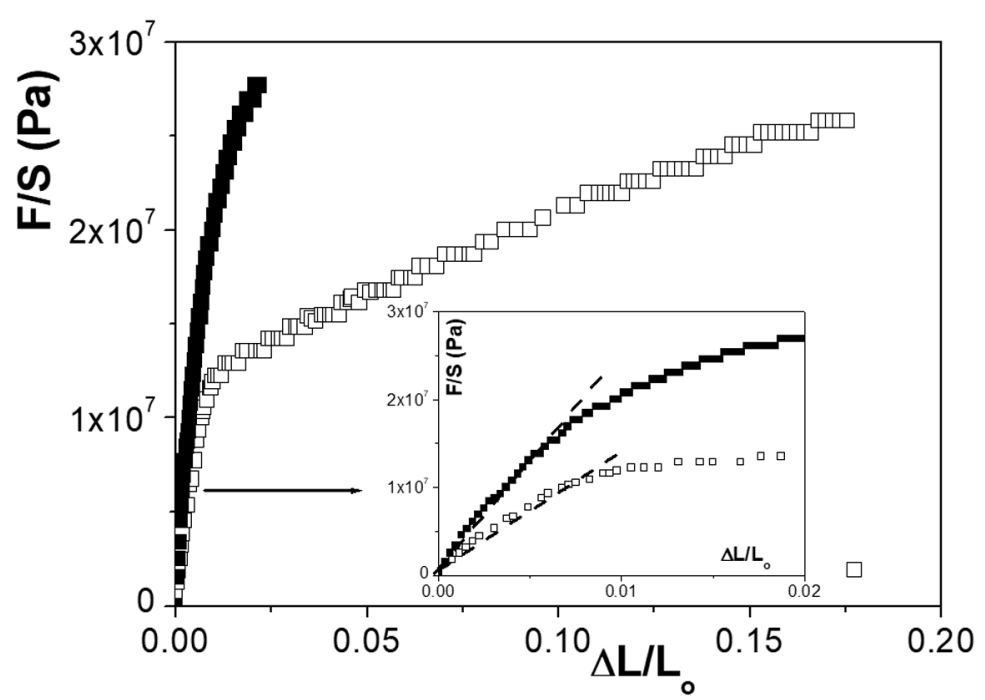

Figure 1. Strain-stress vs. elongation curves for wet $(\square)$ and dry $(\square)$ samples of the $26 \% \mathrm{AlqCl} / 74 \%$ CTA PIM.

Ion transport across a membrane is usually characterized by the ionic diffusion coefficients $\left(D_{i}\right)$ or the ionic transport numbers $\left(t_{i}\right)$, which are related by the following expression: $t_{i}=z_{i} D_{i} / \sum i z_{i} D_{i}$, or $t_{i}=\mathrm{D}_{i} /\left(\mathrm{D}_{+}+\mathrm{D}_{-}\right)$in the case of 1:1 single electrolyte solutions [29], being $\mathrm{z}_{i}$ the valence of ion $i$. Ion transport numbers represent the fraction of the total current $\left(\mathrm{I}_{\mathrm{T}}\right)$ transported for one ion $\left(\mathrm{t}_{i}=\mathrm{I}_{i} / \mathrm{I}_{\mathrm{T}}\right)$ 
and, consequently, in the case of single 1:1 electrolytes they should fulfil that $t_{+}+t_{-}=1$. Ion transport numbers are usually determined from membrane potential $\left(\Delta \Phi_{\text {mbr }}\right)$ values by $[20,30]$

$$
\Delta \Phi_{\mathrm{mbr}}=(R \mathrm{~T} / \mathrm{F})\left(1-2 \mathrm{t}_{-}\right) \ln \left(\mathrm{a}_{1} / \mathrm{a}_{2}\right)=(R \mathrm{~T} / \mathrm{F})\left(1-2 \mathrm{t}_{-}\right) \ln \left(\mathrm{c}_{1} / \mathrm{c}_{2}\right)
$$

where $R$ and $\mathrm{F}$ are the gas and Faraday constants, $\mathrm{T}$ represents the temperature of the system, while $\mathrm{a}_{1}$ and $\mathrm{a}_{2}$ are the activities of the $\mathrm{NaCl}$ solutions at both membrane sides, which can be replaced by solution concentration $\left(c_{1}\right.$ and $\left.c_{2}\right)$ in the case of diluted solutions. Figure 2 shows the variation of membrane potentials with the solution concentration for the $26 \% \mathrm{AlqCl} / 74 \% \mathrm{CTA}$ membrane, as well as the calculated solution diffusion potential values $\left(\Delta \Phi_{\text {dif }^{\circ}}{ }^{\circ}(R T / F)\left(2 t_{+}{ }^{\circ}-1\right) \ln \left(\mathrm{c}_{1} / \mathrm{c}_{2}\right)\right)$, where $t_{+}{ }^{\circ}$ represents the $\mathrm{Na}^{+}$transport number in solution, that is, when there is not any membrane separating the electrolyte solutions (dot-dashed line) [29]. For comparison reasons, membrane potentials for a commercial positively charged ion-exchange membrane (AR204-SZRA-412 by Ionics) are also drawn in Figure 2.

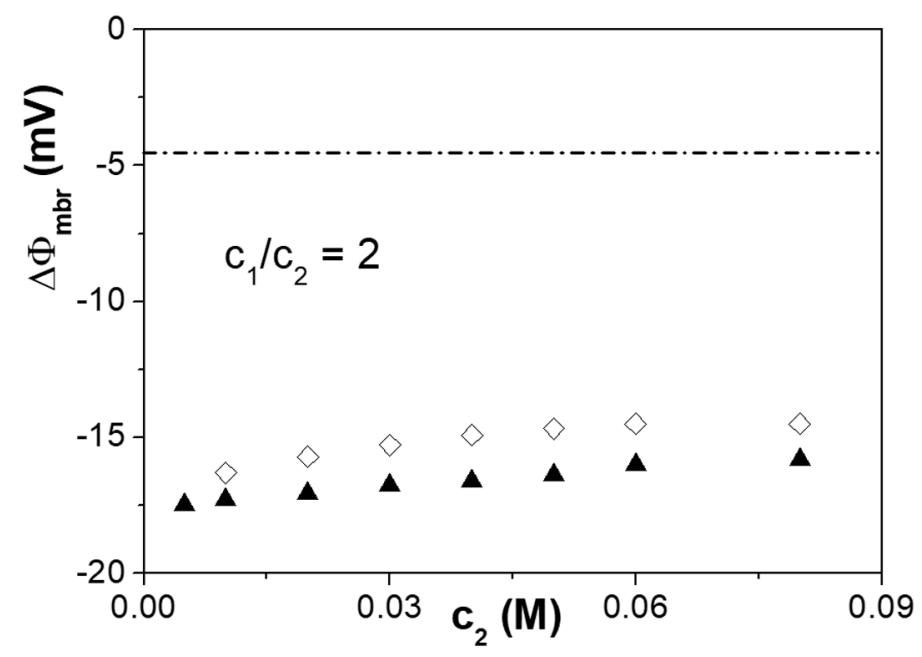

Figure 2. Membrane potential as a function of $\mathrm{NaCl}$ solution concentration: $(\diamond) 26 \% \mathrm{AlqCl} / 74 \% \mathrm{CTA}$ membrane, $(\boldsymbol{\Lambda})$ ion-exchanger AR204-SZRA-412 membrane. Solution diffusion potential: dash dot line.

As it can be observed in Figure 2, $\Delta \Phi_{\text {mbr }}$ values for $26 \%$ AlqCl/74\% CTA and AR204-SZRA-412 membranes are rather similar, being those corresponding to the ion-exchange sample slightly more negative. Moreover, in both cases, $\Delta \Phi_{\mathrm{mbr}}$ values differ significantly from those corresponding to the $\mathrm{NaCl}$ solution, which is an indication of the control of both membranes on ions transport. Ion transport numbers across the PIM were determined by means of Equation (1), and the following average values were obtained: $t_{-}=0.91 \pm 0.03$ and $t_{+}=0.090 \pm 0.003$. Consequently, the diffusive transport of cations across the studied PIM seems to be practically excluded. In fact, taken into account the relationship between ion transport numbers and diffusion coefficients [29], we obtain: $t_{-} / t_{+}=D_{-} / D_{+}=10.1$; that means, $\mathrm{Cl}^{-}$seems to move10 times higher than $\mathrm{Na}^{+}$in the PIM. Ion transport number values are rather similar to those reported by other authors for PIMs obtained for different ILs [20].

Electrochemical impedance spectroscopy (EIS) measurements also provide valuable information on electrical characteristics of membranes. Figure 3 shows the Nyquist plot $\left(-Z_{\text {img }}\right.$ vs. $Z_{\text {real }}$, Figure $\left.3 a\right)$ and the Bode plot ( $-Z_{\text {img }}$ vs. frequency, Figure $3 \mathrm{~b}$ ) obtained for the $26 \%$ Alq336/74\% CTA membrane separating two $0.03 \mathrm{M} \mathrm{NaCl}$ solutions. Two separated contributions associated to the membrane (frequency ranging between $10 \mathrm{kHz}$ and $1000 \mathrm{kHz}$ ) and the electrolyte solution placed between the membrane and the electrodes (frequency $>1000 \mathrm{kHz}$ ) can be observed in Figure 3, which correspond to a depressed semicircle (membrane) and a semicircle (electrolyte solution). This kind of impedance curve is typical of composite systems, in particular it is similar to that exhibited by low 
permeability systems such as dense non-swollen membranes [31] or nanofiltration/reverse osmosis membranes [32-34], and it is related with the significant difference in the electrical characteristics of the two parts forming the composite system: the membrane and the electrolyte solution, respectively. The equivalent circuit for the whole electrolyte(e)/membrane(m) system consists in the addition (series association) of two sub-circuits: a parallel association of a resistance $(\mathrm{R})$ and a capacitor $(\mathrm{C})$ for the electrolyte solution placed between the electrodes and the membrane $\left(R_{e} C_{e}\right)$, plus a parallel association of a resistance and a generalized capacitor $\left(\mathrm{R}_{\mathrm{m}} \mathrm{Q}_{\mathrm{m}}\right)$ for the membrane contribution due to a distribution of relaxation times [35] (see Materials and Methods section).
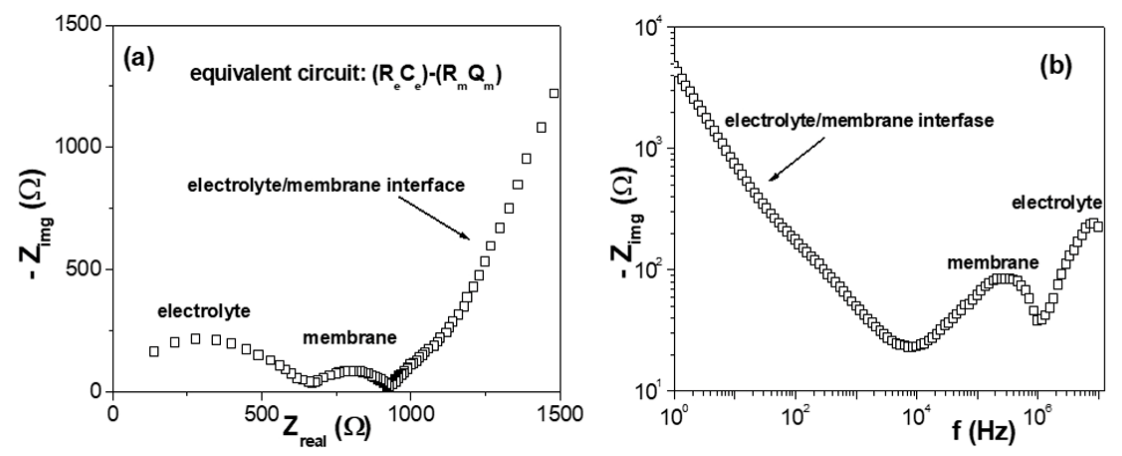

Figure 3. Impedance plots for the $26 \% \mathrm{AlqCl} / 74 \% \mathrm{CTA}$ membrane separating two $\mathrm{NaCl}$ solutions at $0.03 \mathrm{M}$ concentration. (a) Nyquist plot ( $-Z_{\text {img }}$ vs. $Z_{\text {real }}$ ); (b) Bode plot ( $-Z_{\text {img }}$ vs. frequency).

The fit of the impedance curves obtained for the $\mathrm{NaCl}$ concentrations studied (see electrochemical impedance spectroscopy (EIS) measurements in the Experimental section) allows us the determination of the membrane and electrolyte electrical resistance $\left(R_{m}\right.$ and $R_{s}$, respectively) at each $\mathrm{NaCl}$ solution, and Figure 4a shows the dependence $R_{m}$ and $R_{s}$ with electrolyte concentration. Moreover, taking into account the relation between membrane electrical resistance and electrical conductivity $\left(\sigma_{\mathrm{m}}\right)[36]$

$$
\sigma_{\mathrm{m}}=\Delta \mathrm{x}_{\mathrm{m}} / \mathrm{R}_{\mathrm{m}} \mathrm{S}_{\mathrm{m}}
$$

where $\Delta \mathrm{x}_{\mathrm{m}}$ and $\mathrm{S}_{\mathrm{m}}$ represent the membrane thickness and area respectively (assuming the transport takes place through the whole membrane area), variation of membrane electrical conductivity with $\mathrm{NaCl}$ concentration can also be obtained. Figure $4 \mathrm{~b}$ shows the $\sigma_{\mathrm{m}}-\sigma_{\mathrm{s}}$ relationship (membrane conductivity vs. solution conductivity), where the significant barrier effect of the $26 \% \mathrm{AlqCl} / 74 \% \mathrm{CTA}$ PIM on the ion transport can be observed, which could be related to the dense structure and low ionic diffusion across this kind of membranes [20,31].
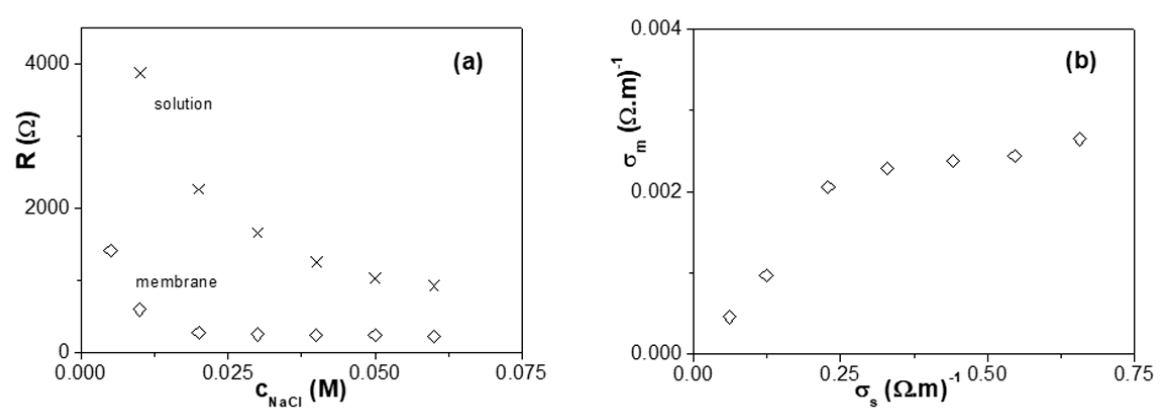

Figure 4. (a) Variation of $26 \% \mathrm{AlqCl} / 74 \% \mathrm{CTA}$ membrane $(\diamond)$ and $\mathrm{NaCl}$ solution $(\times)$ electrical resistance with electrolyte concentration. (b) Membrane conductivity versus solution ( $\mathrm{NaCl}$ ) conductivity.

Diffusive permeability across a membrane, $\mathrm{P}_{\mathrm{s}}$, is another parameter usually determined for membrane characterization, obtained from salt diffusion measurements. According to Fick's first law, 
the solute flux crossing the membrane at steady-state, $\mathrm{J}_{\mathrm{s}}$, and the concentration difference which causes such flux, $\Delta c=\left(c_{d}-c_{r}\right)$, are related by [37]

$$
\mathrm{J}_{\mathrm{s}}=\mathrm{dn} / \mathrm{dt}=\mathrm{P}_{\mathrm{s}} \Delta \mathrm{c}=\mathrm{P}_{\mathrm{s}}\left(\mathrm{c}_{\mathrm{d}}-\mathrm{c}_{\mathrm{r}}\right)
$$

Equation (3) can also be expressed as

$$
\mathrm{dc}_{\mathrm{r}} /\left(\mathrm{c}_{\mathrm{d}}-\mathrm{c}_{\mathrm{r}}\right)=\left(\mathrm{S}_{\mathrm{m}} / \mathrm{Vo}\right) \mathrm{P}_{\mathrm{s}} \mathrm{dt}
$$

Vo and $S_{m}$ are the volume of the receiving cell and the membrane area, respectively. Taking into account the mass continuity: $c_{d}{ }^{o}+c_{r}{ }^{o}=c_{d}{ }^{t}+c_{r}{ }^{t}=$ constant, where $c_{d}{ }^{o}$ and $c_{r}{ }^{o}$ indicate the initial concentrations and $c_{d}{ }^{t}$ and $c_{r}{ }^{t}$ at a time $t$, we obtain the expression

$$
\ln \left(\left[1-\left(2 c_{r}{ }^{t} / c_{d}{ }^{t}\right)\right]=-2\left[S_{m} /\left(\operatorname{Vo} \Delta x_{m}\right)\right] P_{s} t\right.
$$

where Vo represents the cell volume (that means at $t=0$ ). Figure 5 shows time evolution of solution concentration separated by the PIM at a $\mathrm{NaCl}$ donor solution concentration of $0.01 \mathrm{M}$. Diffusive $\mathrm{NaCl}$ permeability across the PIM was determined from the slope of the straight line shown in Figure 5, according to Equation (5), and the value $\mathrm{P}_{\mathrm{s}}=3.8 \times 10^{-8} \mathrm{~m} / \mathrm{s}$ was obtained. This value is similar to that obtained for low permeability or reverse osmosis/nanofiltration membranes [31,32] and, consequently, it seems to be associated to the dense structure of the membrane, which controls the transport when no carried mediated effect is involved.

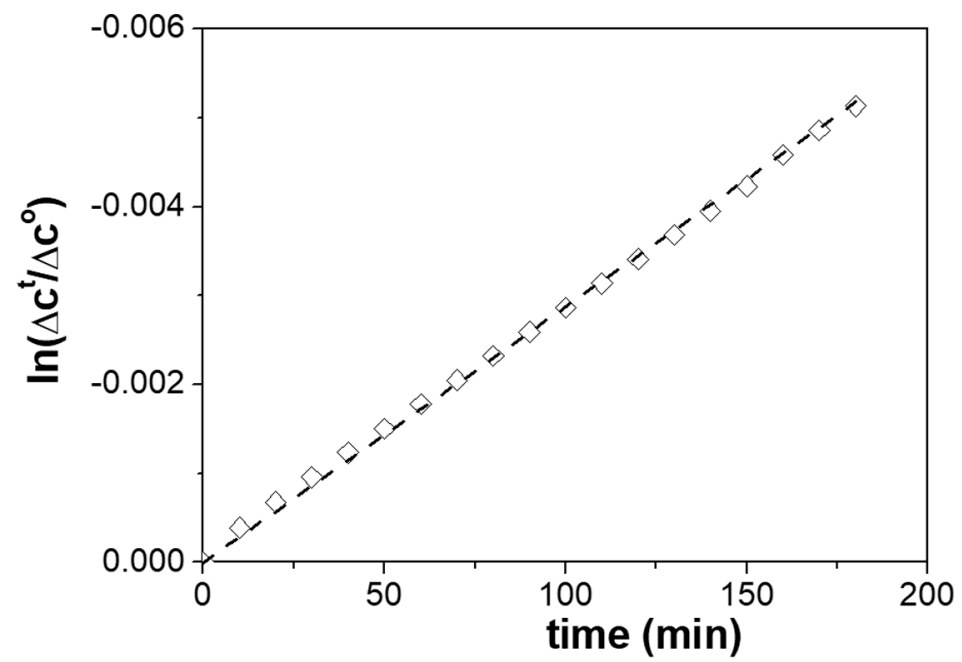

Figure 5. Time evolution of solution concentrations difference ratio at both sides of the $26 \% \mathrm{AlqCl} / 74 \%$ CTA PIM for $\mathrm{NaCl}$ donor concentration $\mathrm{c}_{\mathrm{d}}{ }^{\mathrm{o}}=0.01 \mathrm{M} . \Delta \mathrm{c}^{\mathrm{t}}$ : solution concentration difference at time $\mathrm{t}$; $\Delta \mathrm{C}^{\mathrm{O}}$ : initial solution concentration difference $(\mathrm{t}=0)$.

The low permeability and barrier effect to $\mathrm{NaCl}$ transport exhibited by the PIM determined by different kinds of measurements is of interest for its application in natural water systems (which usually have also $\mathrm{NaCl}$ in solution and/or other salt) since it supports the elimination of their contribution with respect to carried-mediated transport.

Application of the PIM to the Separation of Sulfonamides

The transport kinetics of four sulfonamides across the PIM is a simultaneous combination of extraction and back-extraction reactions occurring in non-equilibrium conditions at the same time. 
The fundamentals of sulfonamides (S) extraction at basic $\mathrm{pH}$ by Aliquat 336 incorporated in a PIM can be described by the generic stoichiometric equation (Equation (6)) [15]

$$
\left[\mathrm{AlqCl}^{-}\right]_{\mathrm{mem}}+\mathrm{Ant}^{-}{ }_{\mathrm{aq}} \leftrightarrows\left[\mathrm{AlqAnt}^{-}\right]_{\mathrm{mem}}+\mathrm{Cl}^{-}{ }_{\mathrm{aq}}
$$

where mem and aq refer to the membrane and aqueous phases, respectively.

As it is indicated in Equation (6), sulfonamides are extracted via formation of an ionic pair with the triocylmethyl ammonium cation while chloride is released in the aqueous solution. Thus, the release of the extracted sulfonamides is possible in a stripping phase containing high amounts of chloride anion.

The transient concentration profiles of sulfathiazole (STZ), sulfapyridine (SPY), sulfamethazine (SMZ), and sulfamethoxazole (SMX) in the feed and stripping solutions as a function of time are presented in Figure 6. The results show an important decrease of the concentration of both STZ (with a thiazole functional group) and SMX (which is the most acidic antibiotic in this study) in the feed solution the first $8 \mathrm{~h}$ of experiment. However, the transport of these species to the stripping phase is much slower. Hence, it can be observed that $60 \%$ of the initial STZ and 50\% of SMX are remain in the membrane after $24 \mathrm{~h}$ of experiment, pointing out that the transport of these species through the dense membrane is the limiting step for their separation. SPY and SMZ exhibit less affinity towards Aliquat 336 due to their less acidic characteristics and their transport is not significant.
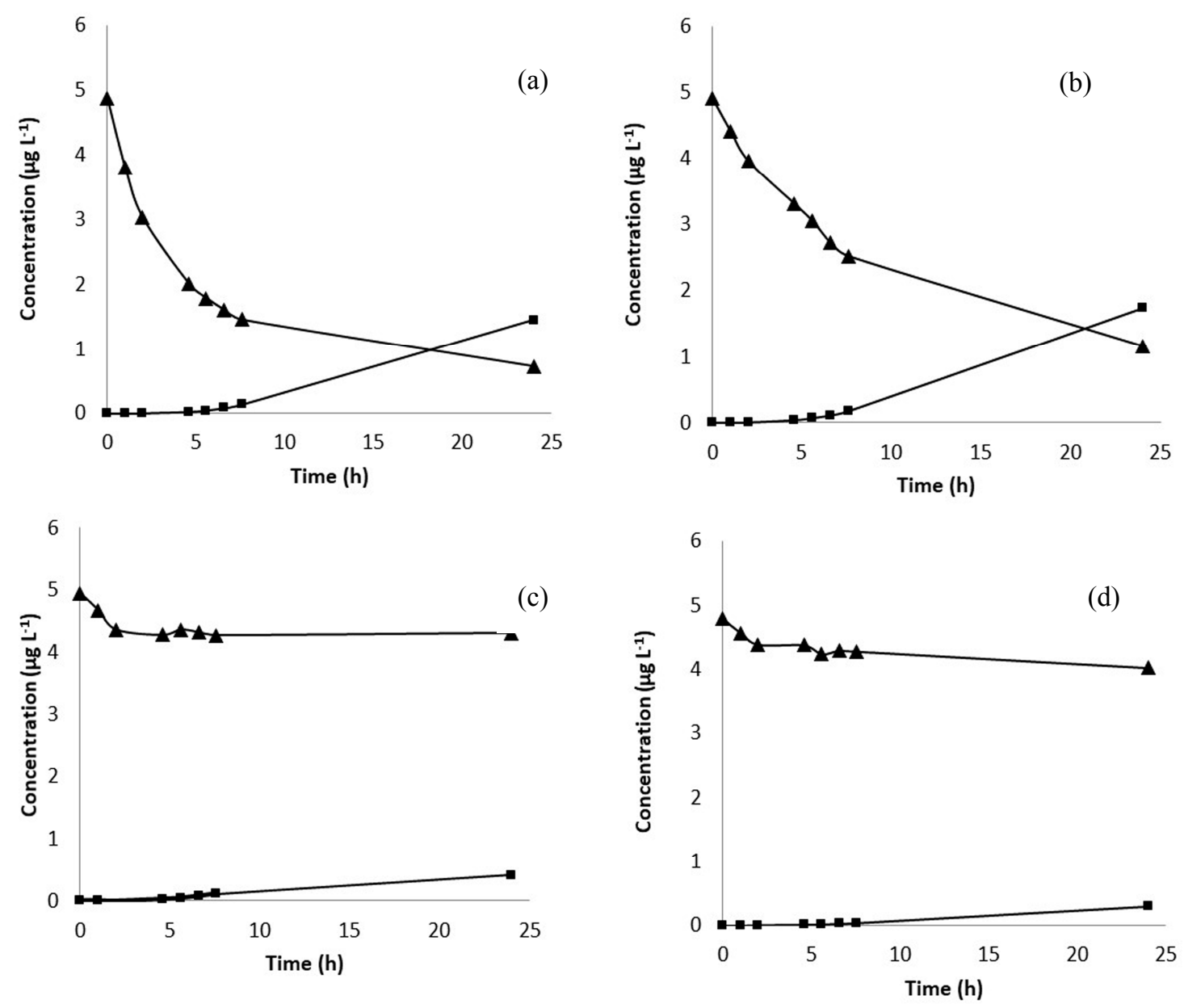

Figure 6. Transient concentration profiles in sulfonamides transport experiments using the $26 \%$ AlqCl/74\% CTA PIM. (a) STZ; (b) SMX; (c) SPY; (d) SMZ. Triangles: feed solution; squares: stripping solution. (Feed solution: $5 \mathrm{mg} \mathrm{L}^{-1}$ of sulfonamides at $\mathrm{pH}$ 9, stripping solution: $1 \mathrm{M} \mathrm{NaCl}$ ). 


\section{Materials and Methods}

\subsection{Membrane Preparation}

PIMs were prepared dissolving $200 \mathrm{mg}$ of cellulose triacetate (CTA) in $20 \mathrm{~mL}$ of chloroform and stirred during $5 \mathrm{~h}$. Afterwards, $1.3 \mathrm{~mL}$ of a $0.5 \mathrm{M}$ Aliquat $336 \mathrm{IL}$ (trioctyl methylammonium chloride or Aliquat $\mathrm{Cl}$ ) solution in chloroform was added to the polymer solution and let stirred $2 \mathrm{~h}$ more. Then, the solution was poured into a flat bottom glass dish and the solvent was allowed to evaporate for $24 \mathrm{~h}$ at room temperature. The resulting film was carefully peeled off from the bottom of the glass dish. Prepared PIMs had a composition of $26 \%$ of AliquatCl and $74 \%$ of CTA and thickness of $30 \pm 3 \mu \mathrm{m}$.

The IL Aliquat 336 and the polymer CTA were purchased from Fluka Chemie (Steinheim, Germany), while other chemicals are from Panreac (Barcelona, Spain).

\section{XPS Measurements}

Membrane surface chemical characterization was performed by analyzing XPS spectra obtained with a Physical Electronics spectrometer PHI 5700 (Physical Electronics, Chanhanssen, MN, USA), using X-ray $\mathrm{Mg} \mathrm{K} \alpha$ radiation $(300 \mathrm{~W}, 15 \mathrm{kV}, 1253.6 \mathrm{eV}$ ) as the excitation source. High-resolution spectra were recorded at a given take-off angle of $45^{\circ}$ by a concentric hemispherical $( \pm 0.1 \mathrm{eV}$ binding energy accuracy) and analyzed following the procedure and experimental conditions already explained in previous papers [24,38]. Measurements were performed with a membrane in wet state $(26 \% \mathrm{AlqCl} / 74 \%$ CTA-w sample), which means, after their immersion in distilled water for $48 \mathrm{~h}$, sample were gently surface dried with paper, and stored for one week to ensure the loss of the adsorbed water; XPS analysis of dry PIM sample (26\% AlqCl/74\% CTA-d) was already reported [18]. Moreover, a cellulose triacetate film (without IL) in dry and wet states (CTA-d and CTA-w, respectively) was also analyzed by XPS for comparison.

\subsection{Elastic Measurements}

Elastic characterization was carried out using a force digital gauge (ES20 model, Mark-10 Corporation, New York, NY, USA), with a maximum tension of $100 \mathrm{~N}$, length accuracy of $\pm 0.01 \mathrm{~mm}$, and at a strength rate of $10 \mathrm{~mm} / \mathrm{s}$, connected to a computer. Elastic measurements were performed with the membrane in air (sample $26 \% \mathrm{AlqCl} / 74 \% \mathrm{CTA}-\mathrm{d}$ ) and placed in a distilled water tank (sample $26 \%$ AlqCl/74\% CTA-w).

\subsection{Electrochemical Characterization: Cell Potentials, Electrochemical Impedance Spectroscopy, and Salt Diffusion Measurements}

Electrochemical characterization of the $26 \% \mathrm{AlqCl} / 74 \%$ CTAPIM was carried out in a dead-end test cell similar to that described in [39], with the solution stirred at $540 \mathrm{rpm}$ to minimize solution concentration-polarization at the membrane surfaces and at room temperature $(25 \pm 2){ }^{\circ} \mathrm{C}$.

Concentration or cell potential $(\Delta \mathrm{E})$ measurements were performed using two reversible $\mathrm{Ag} / \mathrm{AgCl}$ electrodes connected to a digital voltmeter (Yokohama 7552, $1 \mathrm{G} \Omega$ input resistance) and changing the concentrations of the $\mathrm{NaCl}$ solutions at both membrane sides by keeping constant the concentration ratio $c_{1} / c_{2}=2$, from $c_{2}$ ranging between $0.005 \mathrm{M}$ and $0.2 \mathrm{M}$. The membranes were maintained overnight in contact with the lowest concentration solution, but it was renovated previously to start the measurements. Membrane potential $\left(\Delta \Phi_{\text {mbr }}\right)$ or equilibrium electrical potential difference between two solutions of the same electrolyte but different concentrations $\left(c_{1}\right.$ and $\left.c_{2}\right)$ separated by the membrane were obtained from measured cell potential values by subtracting the electrode potential $\left(\Delta \Phi_{\text {elect }}=(R T / F) \ln \left(c_{1} / c_{2}\right)\right.$, where $R$ and $F$ represent the gas and Faraday constants, and $\mathrm{T}$ is the system temperature [37], that is, $\Delta \Phi_{\mathrm{mbr}}=\Delta \mathrm{E}-\Delta \Phi_{\text {elect }}$.

Electrochemical impedance spectroscopy (EIS) measurements were performed with the membrane placed in the dead-end test cell between two $\mathrm{NaCl}$ solutions of the same concentration (concentration ranging between $0.01 \mathrm{M}$ and $0.05 \mathrm{M}$ ), with Pt electrodes connected to a frequency response analyzer 
(FRA, Solartron 1260, England), that is: $\mathrm{NaCl}$ solution (c)/electrode//membrane//electrode/ $\mathrm{NaCl}$ solution (c) system [4]. Measurements were recorded for 100 data points for frequency (f) ranging between $1 \mathrm{~Hz}$ and $10^{7} \mathrm{~Hz}$, at a maximum voltage of $0.01 \mathrm{~V}[4,31,33]$. The impedance of a system, $\mathrm{Z}$, is a complex number, $Z=Z_{\text {real }}+j Z_{i m g}$, derived from experimental data obtained from a broad range of frequencies, which can be separated into real $\left(Z_{\text {real }}\right)$ and imaginary $\left(Z_{i m g}\right)$ parts by algebra rules. For simple and homogeneous systems, $Z_{\text {real }}$ and $Z_{\text {img }}$ are related to the electrical resistance $(R)$ and the capacitance $(\mathrm{C})$ by the following expressions

$$
Z_{\text {real }}=\left(R /\left[1+(\omega R C)^{2}\right]\right) ; Z_{\text {img }}=-\left(\omega R^{2} C /\left[1+(\omega R C)^{2}\right]\right)
$$

where $\omega$ represents the angular frequency $(\omega=2 \pi f)$. The analysis of the impedance data is usually carried out by plotting - Zimg versus Zreal (Nyquist plot), where a semi-circle corresponds to the parallel association of a resistance and a capacitance or (RC) circuit [35]. This description is only valid for homogeneous systems, which present a unique relaxation time $\tau$ (with $\tau_{\max }=2 \pi R C$ ), but in the case of non-homogeneous systems the Nyquist plot is a depressed semi-circle due to a distribution of relaxation times, then a non-generalized capacitor (usually represented as Q) is considered [35]. Moreover, for composite systems consisting of layers with different electrical characteristics, a series association of semi-circles/depressed semi-circles (one for each layer) is commonly obtained [31-34].

For $\mathrm{NaCl}$ diffusion, the membrane separated a donor solution $\left(\mathrm{c}_{\mathrm{d}}=0.01 \mathrm{M}\right)$ from a receiving diluted solution $\left(c_{r}\right)$, which initially was distilled water (that means, $c_{r}{ }^{0}=0$ ) [39]. Time variation of donor and receiving solution concentrations was determined by measuring conductivity changes by means of two conductivity cells, each one submerged in a half-cell, connected to two digital conductivity meters (Crison GLP 31, Barcelona, Spain).

\subsection{Transport Experiments}

Transport across the PIM of four different antibiotics—sulfathiazole (STZ), sulfapyridine (SPY), sulfamethazine (SMZ), and sulfamethoxazole (SMX) - all purchased from Sigma-Aldrich (Steinheim, Germany) was analyzed. Antibiotics stock solutions $\left(250 \mathrm{mg} \mathrm{L}^{-1}\right)$ were prepared in methanol. Experiments were carried out in a permeation cell similar to the one described in [15] in which the mechanically stirred ( $800 \mathrm{rpm})$ feed and stripping solutions $(150 \mathrm{~mL}$ each) were separated by the PIM with an exposed membrane surface area of $11.5 \mathrm{~cm}^{2}$. All experiments were conducted at an ambient temperature of $22 \pm 1{ }^{\circ} \mathrm{C}$.

Working solution containing a mixture of $5 \mathrm{mg} \mathrm{L}^{-1}$ each compound was prepared by appropriate dilution of the stock solutions with deionized water (Milli-Q Plus system, Millipore Iberica S.A., Madrid, Spain) and the $\mathrm{pH}$ was adjusted to 9 with $\mathrm{NaOH}$. Sodium chloride (Carlo Erba, Cornaredo, Italy) was used to prepare the $1 \mathrm{M} \mathrm{NaCl}$ stripping solution. Samples were taken from the feed and stripping solutions at regular time intervals during the $24 \mathrm{~h}$ period of the experiments and were analyzed by an HPLC system (1200 Series Agilent Technologies, Santa Clara, CA, USA) with a diode array detector (1290 Infinity DAD Agilent Technologies, Santa Clara, CA, USA) following the procedure described in [15].

\section{Conclusions}

Electrochemical characterization of a polymer inclusion membrane prepared with the ionic liquid Aliquat $336(26 \%)$ and the polymer cellulose triacetate $(74 \%)$ was performed with a model electrolyte $(\mathrm{NaCl})$ by measuring membrane potential, electrochemical impedance spectroscopy, and salt diffusion. These results enable the estimation of characteristic electrochemical membrane parameters such us the membrane conductivity, and its dependence with $\mathrm{NaCl}$ solution concentration, the diffusive permeability, and the ion $\left(\mathrm{Na}^{+}\right.$and $\left.\mathrm{Cl}^{-}\right)$transport numbers, which clearly show the barrier effect of this membrane to the transport of $\mathrm{NaCl}$. Moreover, membrane contact with water or aqueous solutions seems to affect both chemical surface characteristics and elastic parameters. The separation 
of sulfonamides using this membrane is affected by its dense character, which limits the transport of the organic molecules through it.

Acknowledgments: The financial support of the research project CTM2016-78798-C2-2-P (AEI/FEDER/UE) is acknowledged.

Author Contributions: Juana Benavente performed impedance spectroscopy measurements, interpreted electrochemical characterization and XPS data, co-wrote the manuscript and its final revision. María Isabel Vázquez carried out elastic and diffusion experiments. Virginia Romero was responsible for membrane potential measurements and data analysis. Enriqueta Anticó and Clàudia Fontàs contributed to the preparation of PIMs, doing the transport experiments of antibiotics, interpretation of data, co-writing of the manuscript, and the final revision.

Conflicts of Interest: The authors declare no conflict of interest.

\section{References}

1. Bennet, M.D.; Leo, D.J. Ionic Liquids as stable solvents for ionic polymer transducers. Sens. Actuators A 2004, 115, 79-90. [CrossRef]

2. Welton, T. Room-Temperature Ionic Liquids. Solvents for synthesis and catalysis. Chem. Rev. 1999, 99, 2071-2083. [PubMed]

3. Armand, M.; Endres, F.; MacFarlane, D.R.; Ohno, H.; Scrosati, B. Ionic-liquid Materials for the Electrochemical Challenges of the Future. Nat. Mater. 2009, 8, 621-629. [CrossRef] [PubMed]

4. Fortunato, R.; Branco, L.; Afonso, C.A.M.; Benavente, J.; Crespo, J.G. Electrical impedance spectroscopy characterization of supported ionic liquid membranes. J. Membr. Sci. 2006, 270, 42-49. [CrossRef]

5. Regel-Rosocka, M.; Matema, K. Ionic Liquids in Separation of Metal Ions from Aqueous Solutions. In Application of Ionic Liquids in Science and Technology; Handy, S., Ed.; InTech: Rijeka, Croatia, 2011; pp. 375-798, ISBN 978-953-307-605-8.

6. Ejigu, A.; Walsh, D.A. Electrocatalysis in Room Temperature Ionic Liquids. In Electrochemistry in Ionic Liquids: Application; Torriero, A.A.J., Ed.; Springer: New York, NY, USA, 2015; pp. 483-506. ISBN 978-3-319-15131-1.

7. Albo, J.; Luis, P.; Irabien, A. Carbon dioxide capture from flue gases using a cross-flow membrane contactor and the ionic liquid 1-ethyl-3-methylimidazolium ethylsulfate. Ind. Eng. Chem. Res. 2010, 49, 11045-11051. [CrossRef]

8. Jogelnig, D.; Stojanovic, A.; Galanski, M.; Groessl, M.; Jirsa, F.; Krachler, R.; Keppler, B.K. Greener synthesis of new ammonium ionic liquids and their potential as extracting agents. Tetrahedron Lett. 2008, 49, 2782-2785. [CrossRef]

9. Rubio, A.M.; Tomás-Alonso, F.; Hernández Fernández, J.; Pérez de los Ríos, A.; m. Green Aspect of Ionic Liquids. In Ionic Liquids in Separation Technology; Pérez de los Ríos, A., Hernández Fernández, F.J., Eds.; Elsevier B.V.: Amsterdam, The Netherlands, 2014; pp. 82-92, ISBN 978-0-444-63257-9.

10. Almeida, M.I.S.G.; Cattrall, R.W.; Kolev, S.D. Recent trends in transport and extraction of metal ions using polymer inclusion membranes (PIMs). J. Membr. Sci. 2012, 415-416, 9-23. [CrossRef]

11. Nghiem, L.D.; Mornane, P.; Potter, I.D.; Perera, J.M.; Cattrall, R.W.; Kolev, S.D. Extraction and transport of metal ions and small organic compounds using polymer inclusion membranes (PIMs). J. Membr. Sci. 2006, 281, 7-41. [CrossRef]

12. Rodriguez de San Miguel, E.; Aguilar, J.C.; de Gyes, J. Structural effects on metal ion migration across polymer inclusion membranes: Dependence of transport profiles on nature of active plasticizer. J. Membr. Sci. 2008, 307, 105-116. [CrossRef]

13. Pont, N.; Salvadó, V.; Fontàs, C. Selective transport and removal of $\mathrm{Cd}$ from chloride solutions by polymer inclusion membranes. J. Membr. Sci. 2008, 318, 340-345. [CrossRef]

14. Pospiech, B. Application of Phosphonium Ionic Liquids as Ion Carriers in Polymer Inclusion Membranes (PIMs) for Separation of Cadmium(II) and Copper(II) from Aqueous Solutions. J. Solut. Chem. 2015, 44, 2431-2447. [CrossRef] [PubMed]

15. Garcia-Rodríguez, A.; Matamoros, V.; Kolev, S.D.; Fontàs, C. Development of a polymer inclusion membrane (PIM) for the preconcentration of antibiotics in environmental water samples. J. Membr. Sci. 2015, 492, 32-39. [CrossRef] 
16. Güell, R.; Anticó, E.; Kolev, S.D.; Benavente, J.; Salvadó, V.; Fontás, C. Development and characterization of polymer inclusion membranes for the separation and speciation of inorganic as species. J. Membr. Sci. 2011, 383, 88-95. [CrossRef]

17. Sakai, Y.; Kadota, K.; Hayashita, T.; Cattrall, R.W.; Kolev, S.D. The effect of the counter anion on the transport of thiourea in a PVC-based polymer inclusion membrane using Capriquat as carrier. J. Membr. Sci. 2010, 346, 250-255. [CrossRef]

18. Vázquez, M.I.; Romero, V.; Fontàs, C.; Anticó, E.; Benavente, J. Polymer inclusion membranes (PIMs) with the ionic liquid (IL) Aliquat 336 as extractant: Effect of base polymer and IL concentration on their physical-chemical and elastic characteristics. J. Membr. Sci. 2014, 455, 312-319. [CrossRef]

19. Vera, R.; Gelde, L.; Anticó, E.; Martínez de Yuso, M.V.; Benavente, J.; Fontàs, C. Tuning physicochemical, electrochemical and transport characteristics of polymer inclusion membrane by varying the counter-anion of the ionic liquid Aliquat 336. J. Membr. Sci. 2017, 529, 87-94. [CrossRef]

20. Gizli, N.; Çinarli, S.; Demircioglu, M. Characterization of poly(vinylchloride) (PVC) based cation exchange membrane prepared with ionic liquids. Sep. Purif. Technol. 2012, 97, 96-107. [CrossRef]

21. Kumar, R.; Pandey, A.K.; Sharma, M.K.; Panicker, L.V.; Sodaye, S.; Suresh, G.; Ramagiri, S.V.; Bellare, J.R.; Goswami, A. Diffusional transport of ions in plasticized anaion-exchange membranes. J. Phys. Chem. B 2011, 115, 5856-5867. [CrossRef] [PubMed]

22. Tomás-Alonso, F.; Rubio, A.M.; Giménez, M.; de los Ríos, A.P.; Salar-García, M.J.; Ortiz-Martínez, V.M.; Hernández-Fernández, F.J. Influence of ionic liquid composition on the stability of polyvinyl chloride-based ionic liquid inclusion membranes in aqueous solution. AICHE J. 2016, 63, 770-780. [CrossRef]

23. Kagaya, S.; Ryokan, Y.; Cattrall, R.W.; Kolev, S.D. Stability studies of poly(vinyl chloride)-based polymer inclusion membranes containing Aliquat 336 as a carrier. Sep. Purif. Technol. 2012, 101, 69-75. [CrossRef]

24. Ariza, M.J.; Benavente, J.; Rodríguez-Castellón, E. The Capability of X-ray Photoelectron Spectroscopy in the Characterization of Membranes: Correlation between Surface Chemical and Transport Properties in Polymeric Membranes. In Handbook of Membrane Research: Properties, Performance and Applications; Gorley, S.V., Ed.; Nova Science Publishers, Inc.: New York, NY, USA, 2009; pp. 257-290, ISBN 978-1-60741-638-8.

25. Martínez de Yuso, M.V.; Benavente, J.; Rodríguez-Castellón, E. Use of XPS Technique for Studying Chemical Surface Changes in Modified Membranes. Procedia Eng. 2012, 44, 1204-1206. [CrossRef]

26. Ramos, J.D.; Milano, C.; Romero, V.; Escalera, S.; Alba, M.C.; Vázquez, M.I.; Benavente, J. Water effect on physical-chemical and elastic parameters for a dense cellulose regenerated membrane. Transport of different aqueous electrolyte solutions. J. Membr. Sci. 2010, 352, 153-159.

27. Moulder, J.F.; Stickle, W.F.; Sobol, P.E.; Bomben, K.D. Handbook of X-Ray Photoelectron Spectroscopy; Perkin-Elmer Corporation: Minneapolis, MN, USA, 1992; ISBN 9780962702624.

28. Vázquez, M.I.; de Lara, R.; Benavente, J. Chemical surface, diffusional, electrical and elastic characterizations of two different dense regenerated cellulose membranes. J. Colloid Interface Sci. 2008, 328, 331-337. [CrossRef] [PubMed]

29. Robison, R.A.; Stokes, R.H. Electrolyte Solutions, 2nd ed.; Butterworths: London, UK, 1959; ISBN 0486422259.

30. Porras, B.; Romero, V.; Benavente, J. Effect of acid/basic solutions contact on ion transport numbers and conductivity for an anion-exchange membrane. Desalination Water Treat. 2014, 57, 127-134. [CrossRef]

31. Benavente, J.; García, J.M.; Riley, R.; Lozano, A.E.; de Abajo, J. Sulfonated poly(ether ether sulfone). Characterization and study of dielectrical properties by impedance spectroscopy. J. Membr. Sci. 2000, 175, 43-52. [CrossRef]

32. Benavente, J.; Jonsson, G. Transport of $\mathrm{Na}_{2} \mathrm{SO}_{4}$, and $\mathrm{MgSO}_{4}$ solutions through a composite membrane. J. Membr. Sci. 1993, 80, 275-283. [CrossRef]

33. Cañas, A.; Ariza, M.J.; Benavente, J. Characterization of active and porous sublayers of a composite reverse osmosis membrane by impedance spectroscopy, streaming and membrane potentials, salt diffusion and X-ray photoelectron spectroscopy measurements. J. Membr. Sci. 2001, 183, 135-146. [CrossRef]

34. Benavente, J.; Silva, V.; Pradanos, P.; Hernandez, A.; Palacio, L.; Jonsson, G. A comparison of the volume charge density of nanofiltration membranes obtained from retention and conductivity experiments. Langmuir 2010, 26, 11841-11849. [CrossRef] [PubMed]

35. Ross Macdonald, J.; Kenan, W.R. Impedance Spectroscopy: Emphasizing Solid Materials and Systems; Wiley \& Sons, Inc.: New York, NY, USA, 1987; ISBN 0-471-83122-0. 
36. Benavente, J. Use of impedance spectroscopy for characterization of membranes and the effect of different modifications. In Membrane Modification: Technology and Applications; Hilal, N., Khayet, M., Wright, C.J., Eds.; CRC Press: Boca Raton, FL, USA, 2012; pp. 21-40, ISBN 781439866351.

37. Mulder, M. Basic Principles of Membrane Technology; Kluwer Academic Publishers: Dordrecht, The Netherlands, 1992; ISBN 0-7923-0978-2.

38. Martínez de Yuso, M.V.; Neves, L.A.; Coelhoso, I.M.; Crespo, J.G.; Benavente, J.; Rodríguez-Castellón, E. A study of chemical modifications of a Nafion membrane by incorporation of different room temperature ionic liquids. Fuel Cells 2012, 12, 606-613. [CrossRef]

39. Romero, V.; Vázquez, M.I.; Benavente, J. Study of ionic and diffusive transport through a regenerated cellulose nanoporous membrane. J. Membr. Sci. 2013, 433, 152-159. [CrossRef]

C 2018 by the authors. Licensee MDPI, Basel, Switzerland. This article is an open access article distributed under the terms and conditions of the Creative Commons Attribution (CC BY) license (http:// creativecommons.org/licenses/by/4.0/). 